\title{
Association between Alcohol Consumption and Smoking Habit in the General Population of Rural Nepalese Community
}

\author{
Kishor Khanal $^{1 *}$, Jagdish Chataut ${ }^{1}$
}

\section{Affiliations:}

Department of Community Medicine

Kathmandu University School of Medical Sciences

Dhulikhel, Kavre, Nepal

\section{Correspondence to:}

Kishor Khanal

Department of Community Medicine

Kathmandu University School of Medical Sciences

Dhulikhel , Kavre, Nepal

Email: khanalkishorst@gmail.com

\section{How to cite this Article:}

Khanal K, Chataut J. Association between Alcohol Consumption and Smoking Habit in the General Population of Rural Nepalese Community Ann. Clin. Chem. Lab. Med. 2017:3(1); 22-29

DOI: http://dx.doi.org/10.3126/acclm.v3i1.17719

(C) 2017 Nepalese Association for Clinical Chemistry

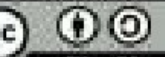

This work is licensed under a Creative Commons Attribution-Share Alike 4.0 International License.

\begin{abstract}
BACKGROUND

Various studies have shown that alcohol consumption and smoking habits are complementary and associated behavior for each other, and these behaviors are influenced by socio-cultural and socio-demographic factors.
\end{abstract}

\section{METHODS}

A community based cross sectional study was conducted on 2013 among 648 general people of rural community of Ramechap district, Nepal. Questionnaires were used to collect information on age, gender, smoking habit, alcohol consumption habit and occupation. Frequency, percentage as well as mean and standard deviation (SD) were calculated as descriptive statistics. To measure the association between alcohol consumption and explanatory variables (i.e. sex, smoking habit and occupation), we used univariate and multivariate logistic regression analysis to calculated unadjusted odds ratios (ORs) and adjusted odds ratios (aORs) with $95 \%$ confidence interval (95\%CI).

\section{RESULTS}

Alcohol consumption was found to be associated with different explanatory variables as follows : smoking habit (Yes: $\mathrm{aOR}=3.90,95 \% \mathrm{CI}=2.58,5.92$ ) , sex (Male: $\mathrm{aOR}=3.64,95 \% \mathrm{CI}=2.27,5.82$ ), occupation (house wife: $\mathrm{aOR}=0.79,95 \% \mathrm{CI}=0.44,1.43$; teacher: $\mathrm{aOR}=1.88,95 \% \mathrm{CI}=0.68,5.24 ;$ government service: $\mathrm{aOR}=1.99,95 \% \mathrm{CI}=1.11,3.59 ;$ and others: $\mathrm{aOR}=$ $0.61,95 \% \mathrm{CI}=0.25,1.47$ ).

\section{CONCLUSION}

Our findings showed an association between alcohol consumption and smoking habit among the population under study.

KEY WORDS: Adult, Alcohol, Gender, Rural Population, Smoking, Socio-cultural 


\section{INTRODUCTION}

Nicotine and alcohol are the most widely used psychoactive substances and they often occur together. Association between consumption of these two substances together has been studied widely in several cross sectional studies. ${ }^{1-6}$ These studies found a strong connection between the use of these two substances together, and in the general population, smokers are more likely to drink alcohol than nonsmokers. ${ }^{1}$ According to the study carried out by Cummins et al. among middle-aged British men, it was found that there exists positive association between smoking and drinking habit, and social class had a strong influence on drinking behavior and weak influence on smoking habit. ${ }^{7}$ Many studies conducted In industrial societies explains that smokers are more likely than others to be drinkers, and drinkers are more likely to be smokers. ${ }^{8}$

Smoking behavior predicts drinking behavior more strongly than the reverse, but according to the study carried out in United States, it was found that

heavy drinkers are quite likely to be heavy smokers, and vice versa. ${ }^{8}$ Many studies have found that the use of either tobacco or alcohol predicts a future dependence of other. ${ }^{9}$ According to Room, smoking and alcohol consumption can be seen as a complementary behavior, ${ }^{8}$ and further Johnson and Jennison said that those two are influenced by a social context, since tobacco and alcohol are often used in the same situation. ${ }^{10}$ The association between smoking and drinking is highly influenced by timing and occasion for those people who both smoke and drink, and for them, smoking is more likely when they drink, and even those who have quit smoking are more likely to smoke again while drinking, ${ }^{11}$. This phenomenon is true for those whose smoking habit has been mostly associated with drinking habit. ${ }^{12}$ Most of the studies on the association between tobacco and alcohol consumption demonstrates a close relationship between the use of these substances together, and the prevalence of alcohol dependence is found higher among people with nicotine dependence. ${ }^{1-12}$ The combined use of alcohol and tobacco may produce a multiplicative increase in cancer rates as well as negative health outcomes. ${ }^{13}$ The use of alcohol and tobacco may be related in two ways: a) intrapersonal linkage, and b) situational linkage, and to explain these links , genetic, coping, pharmacological, personality, learning, and cultural factors should be analyzed and studied. ${ }^{3}$ Tobacco smoking, and alcohol consumption behaviors are strongly influenced with genetic, and socio-cultural factors, so these practices are also regarded as social behaviour. $3,8,14$

According to the survey carried out in Nepal by World Health Organization in 2007, 35.5\% of men, and $15 \%$ of women smoked tobacco products, and $31.2 \%$ of men, and $4.6 \%$ of women used smokeless tobacco. ${ }^{15}$ The overall smoking prevalence in Nepal ranges between $25 \%$ to $73 \%$ in adult men and between $0.8 \%$ to $60 \%$ in adult women across the different regions in the country. ${ }^{16}$ There is a high prevalence of tobacco use among school students, health professional students, and school personnel in Nepal. ${ }^{17}$

The history of alcohol consumption practice is very old in Nepali society, and it is closely related with caste system of Nepal. At present, in Nepali society, social tolerance to alcohol consumption is quite high and it's consumption is common among almost all ethnic groups irrespective of the caste of people, ${ }^{17}$ but traditional Nepalese society was divided on two groups on the basis of alcohol consumption : alcohol non consumers as "Tagadhari", and alcohol consumers as "Matwali". Easily availability and accessibility, socio-psychological circumstances, family drinking environment are some of the contributing factors for alcohol consumption among young people in Nepal. ${ }^{17}$ Most of the studies on the consumption of alcohol are largely based on the small sample size hospital based records, so actual prevalence of alcohol consumers in the whole country is difficult to find, but according to one literature, it is estimated that almost one-half of the Nepalese population consumes alcohol. ${ }^{17}$

To understand the combined use of alcohol and tobacco in the population, the best way is to study on representative sample from the general population, instead of taking sample from alcoholics, who are looking for treatment for their alcohol addiction. ${ }^{18,19}$ The aim of this study was to investigate the association between drinking habit, 
and smoking habit among the rural general population of Ramechap District, Nepal.

\section{METHODS}

A rural community based descriptive cross sectional study was conducted on 2013 among 648 people of Ramechap district, Nepal after obtaining ethical clearance from Institutional review committee (IRC) of Kathmandu University School of Medical Sciences, Dhulikhel, Kavre, Nepal. This study was conducted among the permanent residents of the community whose age were more than or equals to 18 years old. Purposes and objectives of the study were clearly explained in detail to all of the respondents, and verbal consent was taken from all people who participated in the study.

Questionnaires were employed for each individual and it sought information on socio-demographic variables (including Age, Gender, Smoking habit, Alcohol consumption habit, and occupation). All questions of the questionnaire were on Nepali language, and each question was clearly explained to them. Smoking habit was categorized on two categories as current smoker, and currently non-smoker, and alcohol consumption habit was also categorized on two categories as current alcohol consumer, and currently don't consume alcohol. These categorization of smoking and drinking alcohol behaviours were clearly explained to the respondents according to the operational definition defined as, "A person who had smoked more than 100 days or more than 100 cigarettes in his/her life was called an ever smoker. An ever smoker who had not smoked within the last 12 months or within the last 6 months was called an ex-smoker. An ever smoker who had smoked within the past 30 days was called a current smoker." ${ }^{3}$ Drinking behaviours were defined as, "A person who had ever drunk any alcoholic beverage during his/her life was called an ever drinker; this defination excluded childhood sips that the person might have had from an older person's drink. An ever drinker who had not drunk alcohol within the last 12 months was called an ex- drinker. An ever drinker who had drunk alcohol within the last 12 months was called a current drinker." ${ }^{3}$ In this study we were only interested on current smokers, and current alcohol consumers.

Data were collected and entered on MS Excel and was analyzed using SPSS-V22. Frequency, percentage as well as mean and SD were

Table1. Distribution of demographic characteristic along with drinking and smoking habit

\begin{tabular}{|l|l|l|}
\hline Variable & Category & N (\%) \\
\hline Age & $20-29$ & $129(19.9)$ \\
& $30-39$ & $127(19.6)$ \\
& $40-49$ & $229(35.3)$ \\
& $50-59$ & $70(10.8)$ \\
& $60+$ & $93(14.4)$ \\
\hline Sex & Male & $258(39.8)$ \\
& Female & $390(60.2)$ \\
\hline Occupation & Farmer & $306(47.2)$ \\
& Housewife & $209(32.3)$ \\
& Government Service & $75(11.6)$ \\
& Teacher & $19(2.9)$ \\
& Others & $39(6)$ \\
\hline Drinking & Yes & $163(25.2)$ \\
habit & No & $485(74.8)$ \\
\hline Smoking & Yes & $181(27.9)$ \\
habit & No & $467(72.1)$ \\
\hline
\end{tabular}

Table2. Distribution of smoking and drinking habit with respect to sex and age group

\begin{tabular}{|c|c|c|c|c|c|}
\hline \multirow{2}{*}{ Sex } & \multirow{2}{*}{$\begin{array}{l}\text { Age } \\
\text { Group }\end{array}$} & \multicolumn{2}{|c|}{ Drinking Habit } & \multicolumn{2}{|c|}{ Smoking Habit } \\
\hline & & Yes & No & Yes & No \\
\hline \multirow{6}{*}{ Male } & $20-29$ & $\begin{array}{c}24 \\
(21.42)\end{array}$ & $\begin{array}{c}34 \\
(23.29)\end{array}$ & $\begin{array}{c}18 \\
(17.65)\end{array}$ & $\begin{array}{c}40 \\
(25.64)\end{array}$ \\
\hline & $30-39$ & $\begin{array}{c}15 \\
(13.40)\end{array}$ & $\begin{array}{c}26 \\
(17.80)\end{array}$ & $\begin{array}{c}16 \\
(15.69)\end{array}$ & $\begin{array}{c}25 \\
(16.02)\end{array}$ \\
\hline & $40-49$ & $\begin{array}{c}45 \\
(40.18)\end{array}$ & $\begin{array}{c}50 \\
(34.25)\end{array}$ & $\begin{array}{c}40 \\
(39.22)\end{array}$ & $\begin{array}{c}55 \\
(35.26)\end{array}$ \\
\hline & $50-59$ & $\begin{array}{c}15 \\
(13.40)\end{array}$ & $\begin{array}{c}12 \\
(8.22)\end{array}$ & $\begin{array}{c}12 \\
(11.76)\end{array}$ & $\begin{array}{c}15 \\
(9.62)\end{array}$ \\
\hline & $60+$ & $\begin{array}{c}13 \\
(11.60)\end{array}$ & $\begin{array}{c}24( \\
16.44)\end{array}$ & $\begin{array}{c}16 \\
(15.68)\end{array}$ & $\begin{array}{c}21 \\
(13.46)\end{array}$ \\
\hline & Total & 112 & 146 & 102 & 156 \\
\hline \multirow{6}{*}{ Female } & $20-29$ & $\begin{array}{c}12 \\
(23.53)\end{array}$ & $\begin{array}{c}59 \\
(17.40)\end{array}$ & $\begin{array}{c}12 \\
(15.19)\end{array}$ & $\begin{array}{c}59 \\
(18.98)\end{array}$ \\
\hline & $30-39$ & $\begin{array}{c}12 \\
(23.53)\end{array}$ & $\begin{array}{c}74 \\
(21.83)\end{array}$ & $\begin{array}{c}21 \\
(26.58)\end{array}$ & $\begin{array}{c}65 \\
(20.90)\end{array}$ \\
\hline & $40-49$ & $\begin{array}{c}18 \\
(35.30)\end{array}$ & $\begin{array}{c}116 \\
(34.22)\end{array}$ & $\begin{array}{c}29 \\
(36.71)\end{array}$ & $\begin{array}{c}105 \\
(33.76)\end{array}$ \\
\hline & $50-59$ & $\begin{array}{c}6 \\
(11.76)\end{array}$ & $\begin{array}{c}37 \\
(10.91)\end{array}$ & $\begin{array}{c}8 \\
(10.13)\end{array}$ & $\begin{array}{c}35 \\
(11.25)\end{array}$ \\
\hline & $60+$ & $3(5.88)$ & $\begin{array}{c}53 \\
(15.64)\end{array}$ & $\begin{array}{c}9 \\
(11.39)\end{array}$ & $\begin{array}{c}47 \\
(15.11)\end{array}$ \\
\hline & Total & 51 & 339 & 79 & 311 \\
\hline
\end{tabular}


calculated as a descriptive statistics. Chi-square test, binary logistic regression and multivariate logistic regression analysis were carried out for testing the association, to calculate Odds Ratios (ORs) and adjusted Odds Ratios (aORs), to determine the strength of association and direction of association of alcohol consumption with smoking habit, gender, and occupation. Confidence Interval (CI) was taken as $95 \%$ throughout this study. Logistic regression is a multivariate technique that allows studying the association between

Table3. Distribution of drinking habit and smoking habit among respondents

\begin{tabular}{|c|c|c|c|c|c|c|}
\hline Variable & \multicolumn{2}{|c|}{ Drinking Habit } & p-value* & \multicolumn{2}{|c|}{ Smoking Habit } & p-value* \\
\hline Sex & Yes & No & \multirow{3}{*}{$<0.001$} & Yes & No & \multirow[b]{3}{*}{$<0.001$} \\
\hline Male & $112(68.71)$ & $146(30.1)$ & & $102(56.35)$ & $156(33.40)$ & \\
\hline Female & $51(31.29)$ & $339(69.90)$ & & $79(43.65)$ & $311(66.60)$ & \\
\hline \multicolumn{7}{|l|}{ Smoking Habit } \\
\hline Yes & $85(52.15)$ & $96(19.80)$ & \multirow{2}{*}{$<0.001$} & - & - & \multirow{2}{*}{ - } \\
\hline No & $78(47.85)$ & $389(80.20)$ & & - & - & \\
\hline \multicolumn{7}{|l|}{ Occupation } \\
\hline Farmer & $93(57.06)$ & $213(43.92)$ & \multirow{5}{*}{$<0.001$} & $115(63.54)$ & $191(40.90)$ & \multirow{5}{*}{$<0.001$} \\
\hline Housewife & $24(14.72)$ & $185(38.14)$ & & $37(20.44)$ & $172(36.83)$ & \\
\hline Government Services & $30(18.4)$ & $45(9.28)$ & & $16(8.84)$ & $59(12.63)$ & \\
\hline Teacher & $8(4.91)$ & $11(2.27)$ & & $3(1.66)$ & $16(3.43)$ & \\
\hline Others & $8(4.91)$ & $31(6.39)$ & & $10(5.52)$ & $29(6.21)$ & \\
\hline
\end{tabular}

${ }^{*}$ Chi-square test for association

Table4. Univariate and Multivariate logistic regression analysis for associations between Alcohol consumption habit and selected variables

\begin{tabular}{|c|c|c|c|c|c|c|c|c|}
\hline \multirow[b]{2}{*}{ Variable } & \multicolumn{2}{|c|}{ Drinking habit } & \multirow{2}{*}{ ORs } & \multirow{2}{*}{$95 \% \mathrm{Cl}$} & \multirow{2}{*}{$\begin{array}{c}p- \\
\text { value }\end{array}$} & \multirow{2}{*}{$\begin{array}{c}\text { aORs for all } \\
\text { variables } \\
\text { shown in the } \\
\text { table }\end{array}$} & \multirow{2}{*}{$95 \% \mathrm{Cl}$} & \multirow{2}{*}{$\begin{array}{c}\text { p- } \\
\text { value }\end{array}$} \\
\hline & $\begin{array}{l}\text { Yes } \\
n(\%)\end{array}$ & $\begin{array}{l}\text { No } \\
\mathrm{n}(\%)\end{array}$ & & & & & & \\
\hline \multicolumn{9}{|l|}{ Sex } \\
\hline Male & $112(43.4)$ & $146(56.6)$ & 5.10 & $3.47-7.48$ & $<0.001$ & 3.64 & $2.27-5.82$ & $<0.001$ \\
\hline Female & $51(13.1)$ & $339(86.9)$ & 1 (ref.) & & & 1 (ref.) & & \\
\hline \multicolumn{9}{|l|}{ Smoking Habit } \\
\hline Yes & $85(46.9)$ & $96(53.1)$ & 4.42 & $3.02-6.46$ & $<0.001$ & 3.90 & $2.58-5.92$ & $<0.001$ \\
\hline No & $78(16.7)$ & $389(83.3)$ & 1 (ref.) & & & 1 (ref.) & & \\
\hline \multicolumn{9}{|l|}{ Occupation } \\
\hline Farmer & $93(30.4)$ & $213(69.6)$ & 1 (ref.) & & & 1 (ref.) & & \\
\hline House wife & $24(11.5)$ & $185(88.5)$ & 0.30 & $0.18-0.49$ & $<0.001$ & 0.79 & $0.44-1.43$ & 0.43 \\
\hline Teacher & $8(42.1)$ & $11(57.9)$ & 1.67 & $0.65-4.28$ & 0.29 & 1.88 & $0.68-5.24$ & 0.23 \\
\hline $\begin{array}{l}\text { Government } \\
\text { Services }\end{array}$ & $30(40)$ & $45(60)$ & 1.53 & $0.91-2.57$ & 0.11 & 1.99 & $1.11-3.59$ & 0.02 \\
\hline Others & $8(20.5)$ & $31(79.5)$ & 0.59 & $0.26-1.34$ & 0.21 & 0.61 & $0.25-1.47$ & 0.27 \\
\hline
\end{tabular}


two dichotomous variables while adjusting for potential confounding variables. ${ }^{20}$ In this study we considered gender, occupation and smoking habit as potential confounding variables. Thus, the ORs reported in this study, which were obtained through logistic regression analysis, were corrected for some or all of these confounding variables.

If $\mathrm{OR}>1$, we say that a current smoker has a higher risk of becoming a current drinker than a non smoker. (If the $\mathrm{OR}<1$, then a current smoker would have a lower risk of becoming a current drinker than a non-smoker.) When comparing two ORs that are $>1$, the larger OR indicates a stronger association. An OR equal to 1 indicates lack of association. ${ }^{3,20}$ Similar interpretations can be made when studying the association between other pairs of categorical variables.

\section{RESULTS}

Six hundred and forty-eight community people were included in the study out of which majority were female $(390,60.2 \%)$. Minimum and maximum age of participants was 20 years and 90 years old respectively with mean age 42 years and standard deviation 15.03 years. Around one third of the respondents belong to the age group $40-49$ years $(229,35.3 \%)$. A large number of respondents (306, 47.2\%) were farmer by profession. As in any general community, both smokers, and alcohol consumers were present in that society. About a quarter of respondents were alcohol consumers $(163,25.2 \%)$, and smokers (181, $27.9 \%$ ). Among the surveyed people less than a quarter $(85,13.1 \%)$ was both smokers and alcohol consumers. Out of one hundred twelve male alcohol consumers, more than one third of them belongs to the age group 40-49 years $(45,40.18 \%)$, and out of fifty-one female alcohol consumers, about one third of them belong to the age group 40-49 years (18, $35.3 \%$ ). Out of one hundred and two male smokers, more than one third of them belongs to the age group 40-49 ( $40,39.2 \%$ ), and out of seventy nine female smokers, about one third of them belongs to the age group 40 -49 years $(29,36.7 \%)$. According to the occupation, most of the alcohol consumer and smokers were farmers $(93,57.1 \%$ and 115 ,
$63.5 \%$ respectively). Table $1,2 \& 3$.

Alcohol consumption was found to be associated with different explanatory variables as follows : smoking habit (Yes: aOR $=3.90,95 \% \mathrm{CI}=2.58,5.92)$, sex (Male:aOR $=3.64,95 \% \mathrm{CI}=2.27,5.82$ ), occupation (house wife: aOR $=0.79,95 \% \mathrm{CI}$ $=0.44,1.43$; te acher:aOR=1.88,95\% $\mathrm{CI}=0.68,5.24$;government service: $\mathrm{aOR}=$ $1.99,95 \% \mathrm{CI}=1.11,3.59$; and others: $\mathrm{aOR}=$ $0.61,95 \% \mathrm{CI}=0.25,1.47$ ). Table 4 .

\section{DISCUSSION}

According to the Nepal demographic and health survey $2011,30 \%$ of men and $9 \%$ of women aged 15-49 years smoke cigarettes, and $38 \%$ of men and $6 \%$ of women use smokeless products. $^{21}$ Smoking prevalence varies across the country for both men and women (for men it varies from $23.4 \%$ in the Western Region to $34.8 \%$ in the Mid-Western Region, and for women it varies from 5\% in the Eastern Region to $15.6 \%$ in the Mid-Western Region). In rural part of Nepal, $10 \%$ of women and $31 \%$ of men smoke cigarettes. ${ }^{21}$ According to World Health Organization (WHO), smoking prevalence in South Asia is highest for Nepalese women $(28 \%)$, and mid range for Nepalese men $(36 \%){ }^{22}$ All these findings from previous studies are slightly different than our current findings. According to our study carried out among six hundred forty eight people of age group 20-90 years old, out of two hundred fifty eight male, one hundred two ( $39.5 \%)$ were smokers, and out of three hundred ninety female, seventy nine $(20.2 \%)$ were smokers. In total one hundred eighty one $(27.9 \%)$ respondents were smokers. These differences in findings between our study and previous studies might be due to the variation on sample and population under study.

Most studies conducted in Nepal provide little or no information about the consumption of alcohol. ${ }^{17}$ According to our study, out of two hundred fifty eight male respondents, one hundred twelve (43.4\%) were alcohol consumers, and out of three hundred ninety female respondents, fifty one $(13.1 \%)$ were alcohol consumers. In total, one hundred sixty three respondents $(25.2 \%)$ were alcohol consumers. This percentage of female alcohol 
consumers is lower than the study carried out in Sunsari district in 2003 among 2397 females aged 15 years and above where $16.6 \%$ were alcohol consumers. ${ }^{23}$ One of the cause of this differences in consumption of alcohol might be due to the ethnic variation between those two societies, and other cause might be the differences on drinking culture, urbanization, and modernization between those two societies.

In our study we found significant association between drinking habit and smoking habit $(p<0.001)$. Many other studies carried out on different period of time on different countries also established the fact that there is a strong association between smoking and drinking habit. ${ }^{1-9}$ Smokers are more likely to drink alcohol and these behaviors' are complementary to each other. ${ }^{8}$ On the one hand, there is socio-cultural influences on smoking and drinking habit, ${ }^{16}$ and on the other hand behavioral mechanism explains the linkage between those two habits. ${ }^{24}$ In our study we found significant association between gender and smoking habit. Similar type of associations were found on studies carried out among college students in Pokhara-eastern part of $\mathrm{Nepal}^{25}$ and among secondary teachers in Malaysia. ${ }^{26}$

In this study we found significant association between smoking habit and occupation $(p<0.001)$, and this result is not different than the results of the studies carried out in Dharan, eastern part of $\mathrm{Nepal}^{27}$, America ${ }^{28}$ and Iran. ${ }^{29}$ Many studies carried out in different countries have supported the relationship between smoking and occupation. ${ }^{29}$ According to one study, manual laborers, blue-collar workers and people with high stress jobs are more frequently exposed to cigarette smoking than other employees or managers. ${ }^{29}$

Compared with female throughout the world, male are more likely to drink, and consume more alcohol. Biological, and socio-cultural hypothesis explains why men's and women's drinking patterns remain dissimilar. According to human biology, the same amount of alcohol consumed by a female and a male of the same weight will produce a higher level of blood alcohol concentration in the female. ${ }^{30}$ There are several reasons for this, including women's lower body water content, ${ }^{31}$ differences in alcohol dehydrogenase, ${ }^{32}$ metabolism, ${ }^{33}$ and hormone levels ${ }^{34}$. Different socio-cultural researchers have suggested several possible reasons about universal gender differences in drinking behavior. ${ }^{30}$ According to socio cultural point of view: power, sex, risks and responsibilities are the main factors due to which these drinking patterns differs between male and female. ${ }^{30}$ In our study it was found that proportion of male alcohol users is high compared to female, and there is significant association between gender and drinking habit $(p<0.001)$. Similar results were found in the study carried out by Thapa $\mathrm{P}$ and Mishra SR in Nepal. ${ }^{35}$ These findings from Nepal are also supporting those above mentioned Biological and socio-cultural hypothesis regarding gender and consumption of alcohol.

In our study we found significant association between alcohol consumption and occupation $(p<0.001)$. Similar result was found among 214 villagers in the community-based cross-sectional study conducted in a tribal village Meera Tola, Madhya Pradesh India, ${ }^{36}$ and on the other studies carried out in Uganda ${ }^{34}$, Brazil $^{37}$, and Japan. ${ }^{38}$ There are different confounding factors that plays vital role on the establishment of association between occupation and alcohol consumption and these confounding factors are widely discussed on the studies carried out by Marchand A on $2008 .^{39}$

\section{CONCLUSION}

According to our study, alcohol consumption habit was found to be independently associated with smoking habit, sex and occupation. Health education intervention program should be implemented to control both drinking and smoking habit of people. People who smoke are more likely to be alcohol consumer and vice versa, so parallel intervention program focusing on both smoker and alcohol consumers should be implemented to control both of these habits.

\section{LIMITATION}


In this study, self reported information by respondents regarding smoking and alcohol consumption were assumed to be true. Those reports were not verified by bio-chemistry lab test. Alcohol consumption and smoking habit are not considered as a good habit in society, especially due to their adverse effect on health, so it is always possible that selfreporting has introduced biases in the results. To overcome these biases, self reported information should be verified by biochemistry lab test. Further, data on number of cigarette smoked per day, frequency of smoking, amount of alcohol consumptions per day and its frequency were not taken on this study. We believe that collecting such type of micro data will improve the findings of the study.

\section{ACKNOWLEDGEMENTS}

Authors would like to thanks Epidemiologist Dr. Dharma Bhatta, and Public health expert Mr. Pratik Khanal for reviewing this manuscript and providing valuable input and constructive suggestions. We are also thankful to Advocate and Official Translator Mr. Chandra Prasad Luitel for proof reading and editing the language of the manuscript.

\section{CONFLICT OF INTEREST}

None Declared

\section{REFERENCE}

1. Bien TH, Burge R. Smoking and drinking: a review of the literature. International Journal of the Addictions. 1990 Jan 1;25(12):1429-54.

2. Daeppen JB, Smith TL, Danko GP, Gordon L, Landi NA, Nurnberger JI, Bucholz KK, Raimo E, Schuckit MA. Clinical correlates of cigarette smoking and nicotine dependence in alcohol-dependent men and women. Alcohol and Alcoholism. 2000 Mar 1;35 (2):171-5

3. De Leon J, Rendon DM, Baca-Garcia E, Aizpuru F, Gonzalez-Pinto A, Anitua C, Diaz FJ. Association between smoking and alcohol use in the general population: stable and unstable odds ratios across two years in two different countries. Alcohol and Alcoholism. 2007 May 1;42(3):252-7.

4. Gulliver SB, Kalman D, Rohsenow DJ, Colby SM, Eaton CA, Monti PM. Smoking and drinking among alcoholics in treatment: cross-sectional and longitudinal relationships. Journal of studies on alcohol. 2000 Jan; 61(1):157-63.

5. Jackson KM, Sher KJ, Cooper ML, Wood PK. Adolescent alcohol and tobacco use: onset, persistence and trajectories of use across two samples. Addiction. 2002 May 1; 97(5):517-31.

6. John U, Meyer C, Rumpf HJ, Schumann A, Thyrian JR, Hapke U. Strength of the relationship between tobacco smoking, nicotine dependence and the severity of alcohol dependence syndrome criteria in a population-based sample. Alcohol and Alcoholism. 2003 Nov 1; 38(6):606-12.

7. Cummins RO, Shaper AG, Walker M, Wale CJ. Smoking and drinking by middle-aged British men: effects of social class and town of residence. Br Med J (Clin Res Ed). 1981 Dec 5;283(6305):1497-502.

8. Room R. Smoking and drinking as complementary behaviours. Biomedicine \& Pharmacotherapy. 2004 Mar 31;58(2):111-5.

9. Jackson KM, Sher KJ, Wood PK, Bucholz KK. Alcohol and tobacco use disorders in a general population: short-term and long-term associations from the St. Louis Epidemiological Catchment Area Study. Drug and alcohol dependence. 2003 Sep 10;71 (3):239-53.

10. Johnson KA, Jennison KM. The drinking-smoking syndrome and social context. International Journal of the Addictions. 1992 Jan 1;27(7):749-92.

11. Shiffman S, Gnys M, Richards TJ, Paty JA, Hickcox M, Kassel JD. Temptations to smoke after quitting: a comparison of lapsers and maintainers. Health Psychology. 1996 Nov;15(6):455-61.

12. Shiffman S, Hickcox M, Paty JA, Gnys M, Richards T, Kassel JD. Individual differences in the context of smoking lapse episodes. Addictive behaviors. 1997 Nov 1;22(6):797-811.

13. Morgen CS, Bové KB, Larsen KS, Kjær SK, Grønbæk M. Association between smoking and the risk of heavy drinking among young women: a prospective study. Alcohol and Alcoholism. 2008 May 1;43(3):371-375.

14. Bobo JK, Husten C. Sociocultural influences on smoking and drinking. Alcohol Research and Health. 2000 Dec 22;24(4):225-32.

15. Nepal Government, Brief Profile on Tobacco Control in Nepal [internet]; [cited $3^{\text {rd }}$ December, 2016]. Available from: http://www.who.int/fctc/reporting/ party reports/epal 2012 annex2 tobacco profile.pdf

16. Jha $\overline{\mathrm{N}}$, Upadhyay MP, Lakhey $\overline{\mathrm{S}}$, Yadav BK, Baral DD, Ghartichhetri PS. Smoking and smokers in Sunsari, Nepal. J Nep Med Assoc. 1999;38:7-13.

17. Dhital R, Subedi G, Gurung YB, Hamal P. Alcohol and Drug Use un Nepal. Kathmandu: Child Workers in Nepal Concerned Centre (CWIN). 2001 May.

18. Istvan J, Matarazzo JD. Tobacco, alcohol, and caffeine use: a review of their interrelationships. Psychological bulletin. 1984 Mar;95(2):301-326.

19. Hughes JR. Clinical implications of the association between smoking and alcoholism. Alcohol and tobacco: From basic science to clinical practice. 1995:171-85.

20. Woodward M. Epidemiology, Study design and data analysis, $1^{\text {st }}$ ed. Chapman and Hall / CRC, Boca Raton FL, 1999.

21.Nepal MO. New Era, ICF International, 2012. Nepal demographic and health survey. 2011.

22.Engelgau MM. Capitalizing on the demographic 
transition: tackling no communicable diseases in South Asia. World Bank Publications; 2011.

23. Niraul SR, Jha N, Shyangwa PM. Alcohol consumption among women in a district of eastern Nepal. Health Renaissance. 2014 Jan 17;11(3):205-12.

24.Little HJ. Behavioral mechanisms underlying the link between smoking and drinking. Alcohol Research \& Health. 2000 Dec 22;24(4):215-224.

25. Binu VS, Subba SH, Menezes RG, Kumar G, Ninan J, Rana MS, Chhetri SK, Sabu KM, Nagraj K. Smoking among Nepali youth-prevalence and predictors. Asian Pac J Cancer Prev. 2010 Jan 1;11(1):221-6.

26. Al-Naggar RA, Jawad AA, Bobryshev YV. Prevalence of cigarette smoking and associated factors among secondary school teachers in malaysia. Asian Pacific Journal of Cancer Prevention. 2012;13 (11):5539-43.

27. Poudel S, Gurung KD. Prevalence of smoking and perceived health problems among male population of Dharan municipality. Journal of Kathmandu Medical College. 2014 Mar 3;2(3):129-38.

28. Stellman SD, Boffetta P, Garfinkel L. Smoking habits of 800,000 American men and women in relation to their occupations. American journal of industrial medicine. 1988 Jan 1;13(1):43-58.

29. Rajabizadeh G, Ramezani MA, Roohafza H, Pourdamghan N, Khosravi A, Rabiei K, Sarrafzadegan $\mathrm{N}$, Toghianifar N, Zarfeshani S. Association between cigarette smoking and socio-demographics, lifestyle and mental health factors in a sampled Iranian population. Southeast Asian Journal of Tropical Medicineand Public Health. 2011 Jul 1;42(4):977.

30. Obot IS, Room R. Alcohol, gender and drinking problems. Perspectives from low and middle income countries. 2005.

31. Jones BM, Jones MK, Greenblatt M, Schuckit MA. Alcoholism problems in women and children. Grune and Stratton, New York. 1976:103-36.

32. Frezza M, di Padova C, Pozzato G, Terpin M, Baraona E, Lieber CS. High blood alcohol levels in women: the role of decreased gastric alcohol dehydrogenase activity and first-pass metabolism. New England Journal of Medicine. 1990 Jan 11; 322 (2):95-9.

33. National Highway Traffic Safety Administration. National Institute on Alcohol Abuse and Alcoholism. (2000). Sentencing and Disposition of Youth DUI and Other Alcohol Offenses: A Guide for Judges and Prosecutors, Washington, DC. 2006 Jan.

34. Gavaler JS, Deal SR, Thiel DH, Arria A, Allar MJ. Alcohol and estrogen levels in postmenopausal women: the spectrum of effect. Alcoholism: Clinical and Experimental Research. 1993 Aug 1;17(4):786-90.

35. Thapa P, Mishra SR. Gender difference in drinking among the urban squatters of Nepal. Health Prospect. 2016 Mar 6;15(1):11-5

36. Tomar SP, Kasar PK, Tiwari R, Rajpoot SS, Nayak S. Study of alcohol consumption and its sociodemographic determinants in a tribal village in Mandla district. International Journal of Medical Science and Public Health. 2016 May 1;5(5):989-94.

37. Barros MB, Botega NJ, Dalgalarrondo P, Marín-León
L, Oliveira HB. Prevalence of alcohol abuse and associated factors in a population-based study. Revista de Saúde Pública. 2007 Aug; 41(4):502-9.

38. Morikawa Y, Nakamura K, Sakurai M, Nagasawa SY, Ishizaki $M$, Nakashima $M$, Kido $T$, Naruse $Y$, Nakagawa H. The effect of age on the relationships between work-related factors and heavy drinking. Journal of occupational health. 2014;56 (2):141-9.

39. Marchand A. Alcohol use and misuse: what are the contributions of occupation and work organization conditions?. BMC Public Health. 2008 Sep 24;8 (1):333. 